\title{
Errância, contaminações, fluxos esquizos
}

\section{Resumo}

Nos anos 50, o arquiteto e artista Flávio de Carvalho desfilou pelas ruas de São Paulo com o seu Traje de Verão, causando furor e enorme estranheza. Sua ação poética desconcertava os modos de vestir e viver nos Trópicos. Desde os anos 1990, o artista-errante Jayme Fygura circula pelas ruas do Pelourinho, em Salvador, portando trajes rituais, por ele mesmo confeccionados, feitos com materiais recolhidos nas ruas, provocando espanto e temor. Nessa comunicação, tomando Flávio e Jayme como personagens conceituais, buscaremos investigar o que designaremos de fluxos esquizos, cuja potência de invenção contamina as ruas com sua temperatura experimental, disseminando vidas em variação.

Palavras-chave: Arte, fluxos esquizos, contaminações 


\title{
Wandering, contamination and schizo's flows
}

\author{
ROSANE PRECIOSA
}

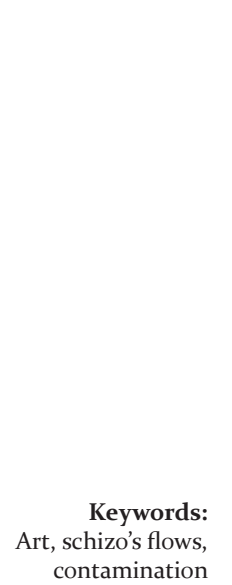

\begin{abstract}
In the ' 50 , architect and artist, a kind of visionary, Flavio de Carvalho, go around the streets of downtown São Paulo using his Summer Costume. No doubt his poetic action questioned ways of dressing and living in the Tropics. Since the late 1990, the artist-wanderer Jayme Fygura roams the streets of Pelourinho, in Salvador, Bahia, wearing some kind of ritual clothing made from waste stuffs picked on the streets, provoking great amazement and even fear. In this communication, taking Flavio and Jayme as conceptual characters, will seek to investigate schizo's flows, whose power of invention contaminates the streets with their experimental temperature, spreading lives in variation.
\end{abstract}


Inicialmente, uma pequena advertência: trago-lhes tão somente anotações, fios soltos ainda. Para meus propósitos aqui, eu me apropriei e revirei alguns conceitos e fui vendo como eles iam funcionando no interior do texto, na medida em que ia escrevendo.

Deleuze nos diz que pensar não é algo natural. Isso me faz lembrar da escritora Virginia Wolf, que em Um Teto Todo Seu vai nos dizer que o pensamento lança o tempo todo sua linha na correnteza. Mas é preciso pescar as ideias. Essas são suas palavras, aqui ligeiramente modificadas. Mas, voltando a Deleuze, para ele, a gente se vê forçado a pensar, pois é preciso dar sentido à força dos signos que nos convocam o tempo todo, tentando um jeito de decifrá-los. Escrever é um modo de dar passagem a esses signos. De acordo com essa lógica, parece que, no final das contas, pensamos-escrevemos não o que já sabemos, não é sobre o domínio de um saber de que se está falando, que nos permite exibir toda nossa erudição, mas da constituição de um corpo teórico que vai aos poucos tramando sentidos, a partir de uma demanda visceral daquele sujeito que escreve. Escrevemos para dar visibilidade ao invisível, para responder ao chamamento das nossas marcas, que o corpo carrega consigo. Para Suely Rolnik, marcas "são os estados vividos em nosso corpo no encontro com outros corpos, a diferença que nos arranca de nós mesmos e nos torna outros" (1993, p. 244).

Esse encontro com os outros corpos não se limita, no entanto, de jeito algum, apenas ao encontro com pessoas, é algo bem mais expandido. Falo das conexões que vamos fazendo vida afora com livros, discos, canções, filmes, roupas, bichos, paisagens, que vão nos multiplicando. Mudamos de natureza, ganhamos em consistência e heterogeneidade. 
Somos escritos pelos estados vividos que ressoam em nosso corpo, nesses encontros com esses outros corpos, o que, necessariamente por serem outros, implica espantos, temores, desassossegos. Afinal, recepcionamos sensações, algo sem nome ainda. E o sujeito que somos, e que vai escrever, não pré-existe ao que escreve, ao contrário, vai se produzindo nesse fluxo de encontros, que vai registrando. Sente o tempo todo que está apenas provisoriamente pronto. Saber disso é contar com um amparo mínimo e necessário para prosseguir.

\section{I}

As cidades modernas foram projetadas sob o signo da Utopia, para recepcionar um "sujeito universal e anônimo" (CERTEAU, 2003, p. 173). No entanto, os mais diversos tipos de sujeitos com ela interlocucionam e vão inventando jeitos de nelas se encaixarem ou desencaixarem, contrariando, na maioria das vezes, os modos de uso esperados. A própria ideia de um centro é substituída por descentramentos. E o que vemos são fluxos de desejos os mais heteróclitos cortando as cidades. Difícil pensar hoje numa cidade, regida pelo princípio da unidade. "Os urbanistas indicam usos possíveis para o espaço projetado, mas são aqueles que o experimentam no cotidiano que os atualizam" (BERENSTEIN, 2007, p.95).

Vemos então emergir nas paisagens urbanas uma multidão "plural, heterogênea, centrífuga" (PELBART, 2010, p.85), que possui a potência de embaralhar códigos, desvirtuá-los, até mesmo desertá-los. Estamos falando aqui de fluxos de desejos nômades que circulam por aí sem autorização, trajando seus modos de pensar, de viver, de amar, de afetar e ser afetado, tecendo o espaço com suas linhas multidirecionais, resultantes dos agenciamentos que vão se dando ao acaso dos percursos. Cavando espaços mais fluidos em meio à solidez monumental da arquitetura das grandes metrópoles-cartões de visita, e seus equipamentos urbanos inadequados, que acabam por esvaziar o espaço público, tornando-o inóspito.

Pois bem, me parece necessário acionar uma escuta micropolítica desses fluxos que se deslocam pelas cidades. Lugar de compartilhamentos sensoriais, de desregramentos, de atrevimentos, de insubordinações, que sob uma ótica reguladora acaba por enxergar tudo que não se encaixa num conceito higienizado, bem comportado de cidade, como degradação, degeneração, arruaça de gente pobre. 


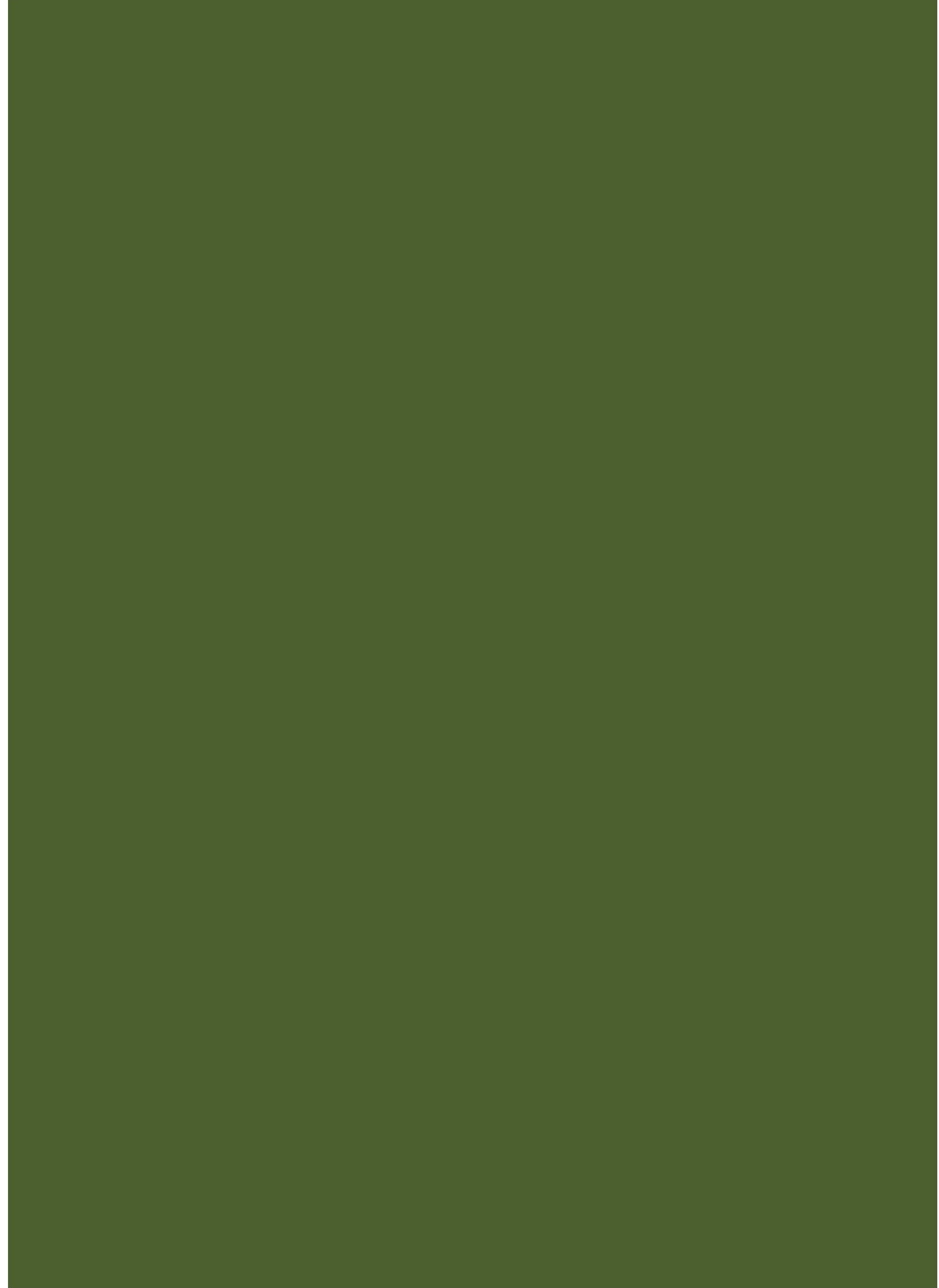


$f=-x$

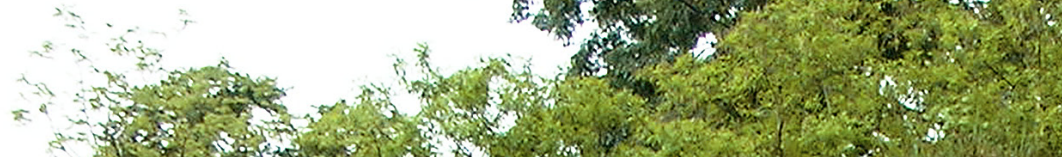

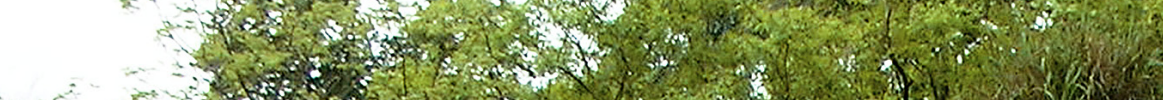

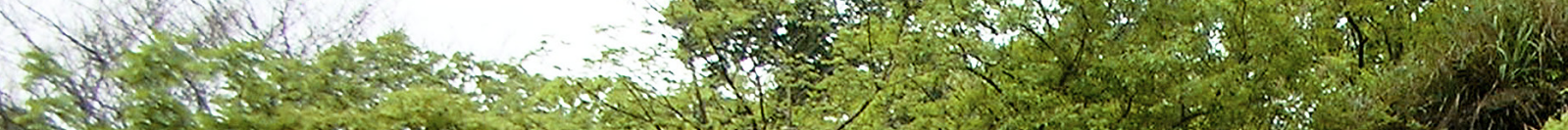
(N. .
$x^{-1}$

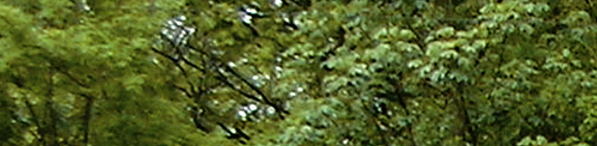

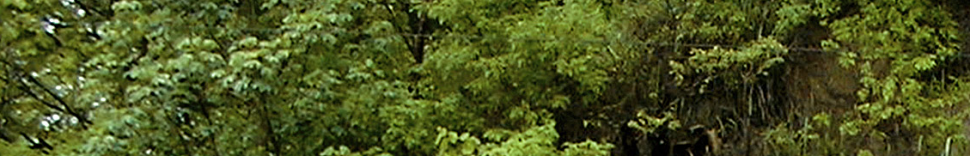

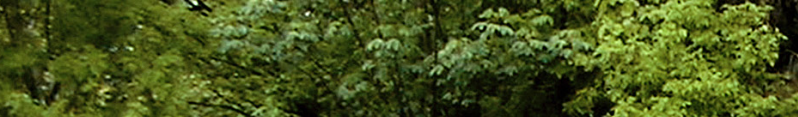
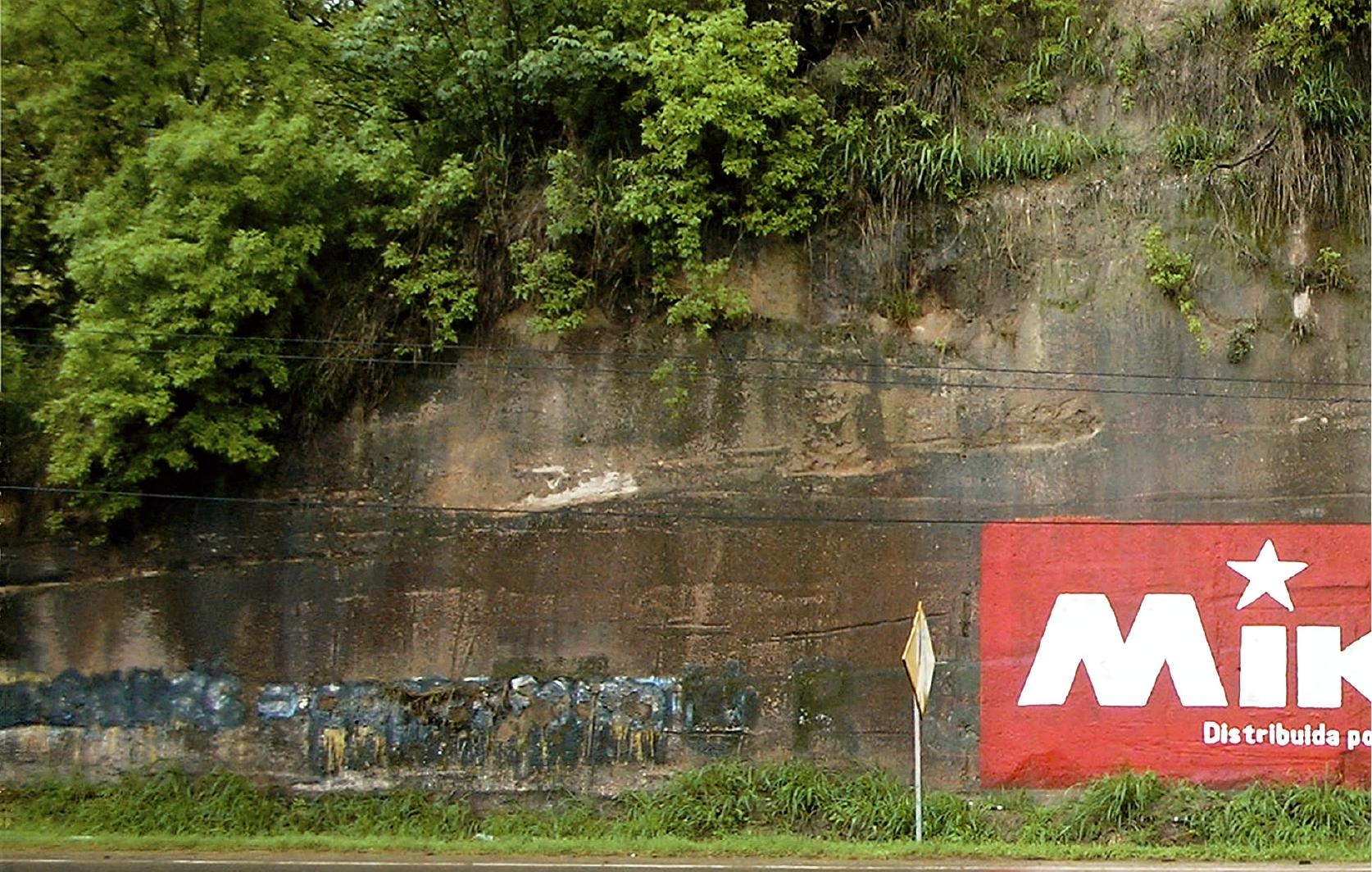

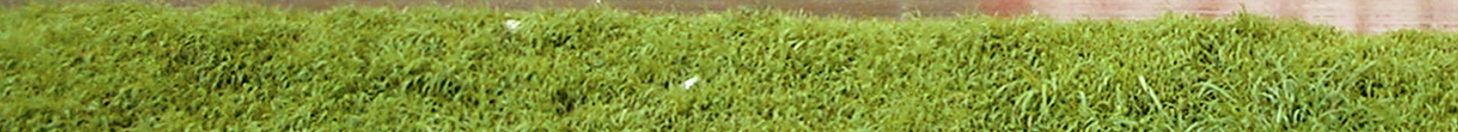

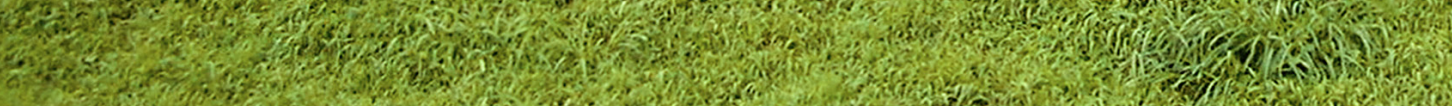

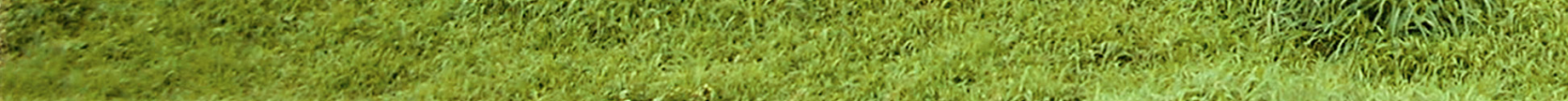

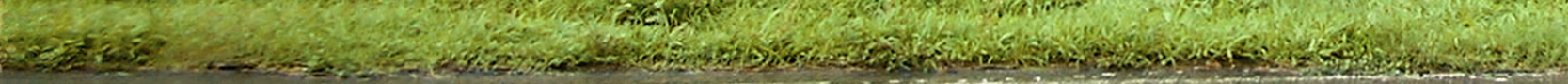




Sabemos bem que sob essa categoria absolutamente inespecífica, a de pobres, são despachadas uma série de representações sem espessura. De modo inteiramente leviano, acabamos por identificar um conjunto de procedimentos cotidianos como coisa de gente pobre, e por isso mesmo, sem valor algum.

Conforme nos dirá Milton Santos:

(...) Há um centro de estudos da violência na USP ao qual devemos boas análises. Mas deveria ser criado também um centro de estudos sobre a solidariedade entre os pobres. Evidente que isso não dá manchete. (...) O discurso estabelecido hoje é que o pobre é violento (In: CORRÊA LEITE et alli, 2007, p.61).

\section{II}

Flávio de Carvalho, além de artista plástico, era engenheiro civil, com diploma da Universidade de Durham, Newcastle, e sabia muito bem o que significava o traçado geometrizado das metrópoles e seus dispositivos disciplinadores. No entanto, o "olho míssil” de Flávio era capaz de enxergar “(...) possibilidades criadoras diante do esmagamento provocado pelos modos tristes de existir" (CERQUEIRA, 2010 p.40). Para ele, são exatamente os sujeitos que trafegam pelas ruas, com suas roupas estapafúrdias, enfeitadíssimas,

marginais descontrolados que falam a um mundo próprio, o mundo da loucura e do sonho (....), os legítimos detentores da grande imaginação e da grande moda. São os supremos criadores da fantasia humana (...). E tão desprezados pelo povo que passa (CARVALHO, 2010, p.9).

Fala-se aqui de um desencaixe, espécie de liberação de uma inscrição social, o que me parece ser uma pista produtiva para se investigar modalidades de criação de modos de existência insubmissas, na medida em que esses sujeitos fronteiriços são buliçosos, não param de se conectar a outros fluxos subjetivos, afetivos, criativos, políticos, ativando outros territórios de existência.

O próprio Flávio, é sabido de todos, praticou essa errância performática mais de uma vez. A primeira delas, realizada em 1931, sua Experiência no. 2, quando o artista atravessou uma procissão de Corpus Christi no centro de São Paulo, portando insolentemente um boné na cabeça, e quase foi linchado. Uma 
outra, que nos interessa mais de perto aqui, sua Experiência no. 3, de 1956. Nessa ocasião, Flávio desfilou pelas ruas do centro de São Paulo, com seu Traje de Verão: mini saia, blusa bufante, meia arrastão e sandálias, causando enorme estranheza. Desafiou todo mundo a pensar nas práticas vestimentares sujeitadas às modas francesas, tão ao gosto das elites locais.

Flávio de Carvalho atribuía à roupa um importante papel, pela sua intimidade com o corpo, e para ele, o corpo importava e muito. Corpo vestido de impetuosidade, que avançava decidido pelas ruas da metrópole, alastrando sua largueza, conectando-se a tantos outros corpos que arrastam seu exílio, uns "párias da família humana”, invocando o poeta Waly Salomão, que empregou essa expressão, fazendo menção à criação dos Parangolés do artista Hélio Oiticica. "O primeiro Parangolé foi calcado na visão de um pária da família humana que transformava o lixo que catava nas ruas num conglomerado de pertences" (SALOMÃO, 1992).

De algum modo, vislumbramos uma existência "pária da família humana”, em Flávio de Carvalho, cujas práticas artísticas situavam-se num lugar fronteiriço, quase inassimilável. Segundo Luiz Camillo Osório, o artista

optou por uma marginalidade e uma dispersão criativa que dificultaram sua inserção histórica. Dificultaram, mas não inviabilizaram, afinal, sua atualidade vem sendo notada pelas novas gerações (2005, p. 10).

Ainda é Camillo Osório quem vai nos dizer duas coisas, que eu sublinharia, neste contexto aqui. A primeira delas, é a de que não é exatamente a Moda que interessa a Flávio, "é a vontade de invenção", ainda que pensar essa dimensão da Moda não escape a este autor: pensar o traje, os trópicos, a existência, a cultura, tudo isso junto compõe sua ação poética. Uma outra, é o fato de que "a sua insensatez coincide com a coragem de exercer uma liberdade criativa que é fértil pelo simples fato de existir" (OSÓRIO, 2005, p. 11). Ao dizer isso, Camillo Osório me auxilia a afirmar uma ideia, a meu ver potente, expressa por Guattari, em companhia de Suely Rolnik, e que diz respeito ao atrevimento de se singularizar. E singularizar-se é resistir aos modos de serialização. Seria travar micro combates, enfrentamentos cotidianos, que ponham em circulação outros desejos, outras sensibilidades, enfim, outros universos de referência (GUATTARI \&ROLNIK,1986). 
Tomar a subjetividade, fazendo dela um campo de experimentos capaz de cometer traições a pactos sociais instalados, em que nos encaixamos, às vezes de forma demasiada, inadvertida e irrefletidamente. Interessante pensar em Flávio, ele também um praticante de desencaixes, procurando entender que desejos no campo social e afetivo rondam os corpos. Conectado a essa força que vem de corpos avariados que perambulam pelas ruas, carregando uma certa exuberância inqualificável, que nos incomoda tanto. Uns desobedientes, que colidem com nosso sistema-vida categórico, e, por onde passam, deixam rastros microbianos, produzindo inquietações no tecido social. E os tememos como a peste, porque ao invés de multiplicar identidades, coisa que nos apazigua, nos faz rodar em círculos de pretensa vida, produzem multiplicidades, produzem vida em variação. E vida em variação é coisa incapturável.

Por puro ressentimento os relegamos à infâmia, os punimos pelo seu atrevimento de serem foragidos da lógica identitária, por escaparem por todos os lados, ainda que muitos, loucos, estão, estiveram, estarão trancafiados, mas suas vozes vazam. E seus gestos e falas contaminam o chão que pisam com seus delírios que remetem a um campo social e histórico, mas cuja expressão se dá em outra cifra e intensidade que não é representacional, não fala de um mundo conhecido, há saltos, interrupções, descontinuidades, silêncios. E delírio $^{1}$ traz uma etimologia interessante. Referindo-se a um contexto da terra, diz respeito aos sulcos abertos pelo arado. E se a riqueza vem da terra, delirar é ser insensato, é dar às costas ao que provê sua existência. Delirar, então, é fugir do caminho reto, ir ao encontro de outras semeaduras, cair fora do mundo sociabilizável, respirar outros ares, tramar outras redes de afetos.

Um fuga é uma espécie de delírio. Delirar é exatamente sair dos eixos ( como 'pirar' etc). Há algo de demoníaco (...) em uma linha de fuga. (...) é próprio do demônio saltar os intervalos, e de um intervalo a outro (...) (DELEUZE, 1998, p. 53).

E os demônios não têm territórios fixos, sequer códigos fixos. Isso é atributo dos deuses.

\section{III}

Para Daniel Lisboa, baiano de Salvador, diretor do curta-metragem "O Sarcófago", cujo protagonista é Jayme Fygura, Jay- 
me é alguém que "quebra a lógica comportamental da cidade, dos homens (...). Um grande rasgo no roteiro de uma existência careta" (CINE ESQUEMA NOVO, 2011).

Mas quem é Jayme Fygura? Não sei se foi ele mesmo quem se atribuiu esse nome. Nunca cruzei com ele em suas andanças pelas ruas do Pelourinho, centro histórico da cidade de Salvador. Aliás, vale a pena lembrar que Pelourinho é uma coluna de pedra, normalmente localizada no centro de uma praça, onde se castigavam criminosos em geral. No Brasil Colônia, era usado para castigar os escravos.

Jayme Fygura é um homem negro, espécie de lenda viva. O que se conta é que ninguém jamais viu seu rosto. No lugar do rosto uma máscara, por ele forjada, bem como sua roupa. Como abordá-lo, então? Para onde teria escapado aquele rosto? Você olha para ele e não vê a que família de rostos pertenceria. Um rosto inabordável, indecifrável. Algo insuportável para nós, que somos viciados em rostos, buscando decifrar emoções demasiadamente humanas por detrás deles. Afinal, um corpo aprende cedo a ter um rosto e nele reconhece sua identificação, seu pertencimento à cultura. Há sempre uma expectativa de que ele seja desvendado. E como seria então ver se desarticular esse rosto desse destino-pessoa, que passa a diagramar no lugar do rosto outras paisagens: nele imprime trajetos de existência. Jayme Fygura parece desencantar o rosto dos estados confinados que o frequentam, essa espécie de triste moldura que habitamos.

Impossível não lembrar das palavras de Deleuze ao chamar a produção do pintor Francis Bacon de figural. Tentador é associar o nome Fygura à "(...) figura, mas figura desfigurada, despojada da função figurativa” (MACHADO, 2009, p. 227). Recuo da representação do humano para dar lugar à sua deliberada deformação, tensionando esse modo de representação.

Jayme é uma cabeça-corpo que se desloca vestindo sua máquina de guerra pulsante, e esse termo guerra aí é sutil, algo impetuoso que inventa novos espaços-tempos para serem vividos, uma poderosa sucata estética, devolução dos dejetos que vai recolhendo nas ruas. Traje feito para performar seu épico ordinário contundente, que se renova a cada dia, de forma incansável. Jayme é um homem negro que vive em situação de pobreza. Palavra, como nos adverte Monique Cerqueira, que é usada para além de uma designação, "é um lugar de confinamento (...)" (CERQUEIRA, 2010, p. 23). E Jayme, 
trajando sua armadura-sucata, vai traçando territórios, resistindo, despachando as forças nefastas que desautorizariam sumariamente sua existência, espantando os signos de insuficiência e pobreza que ameaçam nele se grudar.

Como nos dirá Mila Goudet:

não se trata de estetizar a pobreza através do viver exótico (...), nem de mascarar a terrível violência em meio à qual vivem os favelados, mas de ampliar a potência cultural dessas populações e, através dessa ampliação, desejar outras definições mais emancipatórias para esta situação urbana (2010, p.99).

Convivemos diariamente nas ruas com uma legião de errantes, que exibem seus bastardos mundos, dialogam intensamente com o que encontram pelo caminho, investigando a potência daquelas coisas virarem outras. Suas invenções são feitas a partir do material de descarte, que a cidade expele.

\section{IV}

Sabemos que ninguém sai ileso da potência enredadora da vida, dos tsunamis afetivos, de onde sairemos outros: ora nadaremos ora afundaremos. Alguns afundam, e seus gestos eloqüentes ou a falta deles, nos trazem notícia de suas dores psíquicas. Outros, e nesse rol podemos incluir Jayme Fygura, insistem. Diagramam outras estranhas constelações de forças, instauram um espaço concreto de criação.

Talvez seja oportuno lembrar das palavras de Félix Guattari, ao dizer:

(...) A arte não é somente a existência de artistas patenteados (grifo meu), mas também de toda uma criatividade subjetiva que atravessa os povos e as gerações oprimidas, os guetos, as minorias (GUATTARI, 1992, p.115).

Daí nosso espanto quando imprevistas fabulações, fora do circuito da arte, cruzam nossos caminhos e nos arrebatam, transtornando nossos referenciais familiares. O que nos aturde é que parece existir um estado de Arte que desborda do que reconhecemos como Arte, via seus modos habituais de legitimação.

No documentário Cildo, do diretor Gustavo Moura, o artista, na abertura do filme faz um relato emocionado, que dialoga com o que acabo de dizer. Ele diz que, por volta de 
seus sete anos, morou com a família na casa de sua avó materna, e que qualquer coisa diferente da rotina era motivo de curiosidade. Certa vez, num final de tarde, passou por lá um andarilho que arrumou um canto para ficar, próximo à casa da avó, e ali acendeu uma fogueira. Na manhã seguinte, Cildo acordou bem cedo, antes de todos, e foi até o lugar onde o andarilho passou a noite, lugar que conhecia bem. Ele já havia ido embora, mas deixou lá uma casa em miniatura, perfeita: paredes, telhado, janelas que abriam, tudo feito de gravetos. Alguém havia passado a noite toda trabalhando, diz Cildo, e deixou aquilo lá, para pessoas que não conhecia. Essa teria sido, seguramente, uma das coisas que o fizeram escolher as artes plásticas.

Flávio de Carvalho instalando-se num lugar de fronteira estética, conquistou uma refinada escuta ao que se passava nas ruas. Sabia que alguns daqueles corpos errantes afundaram nas "paixões tristes", desfiguraram-se, decompuseram-se. Alguns, esquizos crônicos que nos noticiam com eloquência suas dores psíquicas, nelas estão encarcerados, imobilizados. Outros, como Jayme Fygura, são fluxos de vida desconcertantes, e avançam sobre nós exibindo sua exuberante vontade de potência, e não de poder.

(...) Enquanto um sujeito potente é um criador por excelência, o poderoso é aquele que sempre estará aliado às forças de manutenção, fazendo com que tudo permaneça absolutamente como está (...) (CERQUEIRA, 2010, p.24).

Ao se falar sobre esquizos, é fundamental que se faça uma distinção, e aqui, recorro às palavras de Peter Pelbart:

Uma coisa é o esquizofrênico como tipo psicossocial, essa entidade produzida, hospitalar, clínica, artificial. Outra coisa é o esquizofrênico tomado como personagem conceitual, portador de fluxos desterritorializados, e descodificados, processualidade pura (200o, p.161).

Podemos dizer que ambos, Flávio de Carvalho e Jayme Fygura, aqui tomados como personagens conceituais, aqueles que nos impulsionam a criar conceitos, são, cada um, a seu modo, portadores de fluxos esquizos. Avançaram sobre os códigos sociais instituídos, produzindo pequenos terremotos, exercitando uma poética das instabilidades. Deliraram, saíram do sulco. E isso é motivo de muita alegria. 


\section{Referências}

BERENSTEIN, Paola. Corpografias Urbanas - o corpo enquanto resistência. In: Resistências e Espaços Opacos. Salvador: Cadernos PPG - FAUUFBA, 2007.

CAMILLO OSÓRIO, Luiz. Eu Sou Apenas Um! In: Cadernos VídeoBrasil - performance. São Paulo, 2005.

CARVALHO, Flávio. A Moda e o Novo Homem. Rio de Janeiro: Azougue Editorial, 2010.

CERQUEIRA, Monique Borba. Pobres, Resistência e Criação. São Paulo: Editora Cortez, 2010.

CERTEAU, Michel de. A invenção do Cotidiano - 1. artes do fazer. Petrópolis: Editora Vozes, 2003.

CINE ESQUEMA NOVO. Entrevista: Daniel Lisboa (BA) fala sobre “O Sarcófago". Disponível em<http://cineesquemanovo.wordpress.com/2011/o4/11/entrevista-daniel-lisboa-ba-fala-sobre-o-sarcofago/> Acesso em 11/5/2012.

CORRÊA LEITE, José; CARVALHO DE, Mônica; SEABRA, Odette. Território e Sociedade: entrevista com Milton Santos. São Paulo: Editora Fundação Perseu Abramo, 20 ed., 30 reimpressão, 2007.

DELEUZE, Gilles. Diálogos. São Paulo: Editora Escuta, 1998.

GOUDET, Mila. Urbanismos Barrocos e espaços comunicacionais: entre o formal e o informal em São Paulo e na América Latina. Tese de Doutorado, PUC/SP, 2010.

GUATTARI, Félix. Caosmose. Um novo paradigma estético. São Paulo: Editora 34, 1992.

GUATTARI, Félix e ROLNIK, Suely. Micropolítica: cartografias do desejo. Petrópolis: Editora Vozes, 1986.

MACHADO, Roberto. Deleuze, a Arte e a Filosofia. Rio de Janeiro: Editora Zahar, 2009.

PELBART, Peter Pál. A Vertigem por um Fio - políticas da subjetividade contemporânea. São Paulo: Editora Iluminuras/ FAPESP, 2000.

PERRONE, Cláudia Maria. Esquizoanálise. In: Abecedário educação da diferença. Orgs: Aquino, Julio Groppa e Corazza Sandra Mara. Campinhas: Editora Papirus, 2009.

ROCHA LIMA, Marcos Eduardo. Três Esquizos Literários. Porto Alegre: Editora Sulina/ UFRGS, 2010.

ROLNIK, Suely. Pensamento, Corpo e Devir: uma perspectiva ético/estética/política no trabalho acadêmico In: Cadernos de Subjetividade, v.1 n.2: 241-251. Núcleo de Estudos e Pesquisas da Subjetividade, Programa de Estudos Pós Graduados de Psicologia Clínica, PUC/SP. São Paulo: set./fev. 1993. 
SALOMÃO, W. Homage, in Hélio Oiticica, Catalogue de la Galerie Nationale du Jeu de Paume à Paris, 1992.

NOTAS

1. Essas ideias estão contidas no livro Três Esquizos Literários, de autoria de Eduardo Rocha Lima, publicado pela Editora Sulina em 2010.

Recebido em: 03/04/13

Aceito em: 03/04/13 
ROSANE PRECIOSA

rosane_preciosa@yahoo.com.br

Professora do Instituto de Artes e Design da UFJF. Em 2010, publicou

o livro Rumores Discretos da Subjetividade pela editora Sulina em parceria com a UFRGS. Este livro se origina de sua tese de doutorado, defendida, em 2002, no Núcleo de Estudos e Pesquisas da Subjetividade Contemporânea da PUC/SP. 
